\title{
HIBAH WEBSITE PROMOSI DAN PELATIHAN MICRO TEACHING BAGI PENGAJAR PADA BIMBINGAN BELAJAR DHARMA PUTRA
}

\author{
Yoki Firmansyah ${ }^{1}$, Deasy Purwaningtias ${ }^{2}$, Yeni Mustika, Tarina Dashela ${ }^{4}$ \\ 1,2,3,4 Program Studi Sistem Informasi \\ Fakultas Teknik dan Informatika, Universitas Bina Sarana Informatika \\ Jalan Abdurrahman Salah No 18 , Pontianak, Kalimantan Barat \\ yoki.yry@bsi.ac.id 1 , deasy.dwg@bsi.ac.id 2, yeni.yem@bsi.ac.id 3, tarina.tdl@bsi.ac.id 4
}

\begin{abstract}
In the era of globalization, technology has become a necessity to support work, for example for educational institutions, one that can take advantage of technology such as websites is the Bimbel Dharma Putra educational institution, the delivery of information has been using conventional methods, namely by sharing news on WhatsApp grub, social media, even mouth to mouth. Even though having a personal website can better publish institutional profiles and information such as schedules, fees, classes and other information and can provide added value to the public. In addition, to improve the quality of the teaching teachers, of course Dharma Putra learning guidance also requires training to improve the teaching skills and abilities of the teachers in the tutoring, therefore a website is needed for promotion and micro teaching training is needed for teachers in the Dharma Putra training. As for the method used, namely by providing training with the aim that if you have a website, it can promote and disseminate information better, and the ability of the teachers to be improved.
\end{abstract}

Keywords: Website; Micro Teaching; Tutoring.

\begin{abstract}
Abstrak
Pada masa era globasisasi, Teknologi menjadi kebutuhan sebagai penunjang pekerjaan contohnya untuk lembaga pendidikan, salah satu yang dapat memanfaatkan teknologi seperti website adalah lembaga pendidikan Bimbel Dharma Putra, penyampaian informasi selama ini menggunakan cara yang konvensional yaitu dengan cara membagikan berita di whatsapp grub, social media, bahkan mulut kemulut. Padahal dengan memiliki website pribadi dapat mempublikasikan profil lembaga, dan informasi seperti jadwal, biaya, kelas dan informasi lainnya secara lebih baik dan dapat memberikan nilai tambah di mata masyarakat. Selain itu untuk meningkatkan kualitas para guru pengajar tentunya bimbingan belajar dharma putra juga memerlukan pelatihan untuk meningkatkan skill dan kemampuan mengajar dari pengajar yang ada di bimbel tersebut, maka dari itu diperlukan sebuah website untuk promosi dan diperlukan pelatihan micro teaching untuk pengajar di bimbel dharma putra, adapun metode yang digunakan yaitu dengan memberikan pelatihan dengan tujuan apabila memiliki website maka dapat mempromosikan dan menyebarkan informasi dengan lebih baik, dan kemampuan para pengajar menjadi lebih meningkat.
\end{abstract}

Kata Kunci: Website; Micro Teaching; Bimbingan Belajar

\section{PENDAHULUAN}

Pada masa era globasisasi, komputer sudah menjadikan kebutuhan sebagai alat penunjang untuk mempermudah prjaan terutama untuk sebuah instansi pemerintah atau perusahaan.[1] Teknologi banyak digunakan sebagai sarana promosi dan informasi khususnya pada bidang website yang saat ini sangat berperan dalam penyampaian informasi [2]

Sekarang ini informasi melalui web sudah menjadi alat yang sangat penting dalam pegolahan data untuk menghasilkan sebuah informasi.[3] internet tidak hanya digunakan untuk memperoleh informasi saja, melainkan dapat digunakan sebagai media untuk melakukan bisnis dengan membangun sebuah website [4]

Website itu sendiri adalah salah bentuk media massa yang publikasinya melalui jaringan internet. Website in dapat diakses 24 jam dan dari belahan bumi manapun. Kelebihan lain dari publikasi melalui website adalah kemampuan interaktif dan penyebaran yang sangat cepat. [5]

Melalui website, institusi pendidikan dapat mempublikasikan profil lembaganya dan dapat memberikan informasi tentang lembaga 
pendidikan kepada calon siswa. Informasi dapat berupa jadwal, biaya, kelas dan lain sebagainya yang dapat memperjelas bagi siswa dan orang tua yang akan memasukan anak mereka ke lembaga kursus tersebut.[6]

Salah satu lembaga pendidikan Bimbingan Belajar Dharma Putra yang berlokasi di jalan Tanjung Raya 2 Gg. Sukahayu Kompleks Damai Residance 2 No. B1 merupakan lembaga pendidikan untuk tingkat Pra SD, SD,SMP dan SMA. Mata Pelajaran yang ada di lembaga tersebut untuk tingkat SD dan SMP adalah matematika dan fisika. Sedangkan untuk tingkat SMA hanya matematika. Lembaga pendidikan tersebut memiliki 6 guru pengajar dengan latar belakang pendidikan sarjana pendidikan. Memiliki 1 administrasi. Pemilik dari lembaga tersebut adalah bapak Yuda Firlana,Spd.I yang berlatar pendidkan sarjana pendidikan agama islam.

Lembaga pendidikan Dharma Putra merupakan lembaga pendidikan yang masih baru beroperasi sehingga memerlukan website profil sebagai sarana promosi dan sebagai pelatihan micro teaching bagi pengajar dan pemilik lembaga pendidikan tersebut. Kurangnya masyarakat disekitar lembaga pendidikan tersebut mengenal dan mengetahui keberadaannya.

Selain kurang dikenalnya lembaga pendidikan, berdasarkan observasi dan wawancara yang dilakukan maka didapatkan pula permasalahan yaitu kurangnya manajemen waktu pengajaran oleh para pengajar di bimbel tersebut, dan dibutuhkan peningkatan skill dan kemampuan mengajar untuk para pengajar.

Micro teaching merupakan salah satu cara latihan mengajar atau melatih yang diisolasikan agar keterampilan mengajar dasar yang sederhana dengan mudah dapat dikuasai[7]. Tujuan pembelajaran micro teaching secara umum adalah untuk melatih dan mempersiapkan mahasiswa sebagai calon guru dalam menghadapi pekerjaan mengajar sepenuhnya di muka kelas dengan memiliki pengetahuan, keterampilan, kecakapan dan sikap sebagai guru yang professional [7].

Maka dari itu berdasarkan permasalahan yang didapatkan ketika melakukan observasi dan wawancara maka didapatlah kesimpulan bahwa bimbel dharma putra membutuhkan sebuah website untuk melakukan promosi dan membutuhkan pelatihan micro teaching untuk para pengajar dengan tujuan untuk meningkatkan eksistensi bimbel di masyarakat dan meningkatkan kemampuan para mengajar dalam memberikan pendidikan kepada siswa yang ada di bimbel dharma putra.

\section{METODE PENGABDIAN MASYARAKAT}

Dalam pelaksanaannya pengabdian masyarakat ini dilakukan dalam beberapa tahapan, dimana tahapan yang dimaksud tergambarkan dalam diagram dibawah ini :

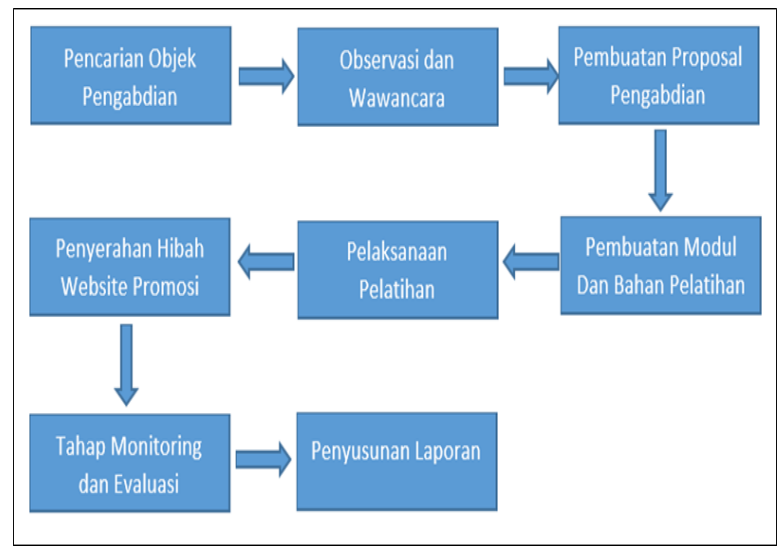

Gambar 1. Diagram Metode Pelaksanaan Pengabdian

Pada Gambar 1 dapat dilihat langkah pertama yang dilakukan adalah dengan mencari objek atau tempat yang akan di jadikan lokasi ataupun sasaran pengabdian, lalu berikutnya setelah menemukan sasaran maka dilakukan observasi dan wawancara terhadap objek pengabdian, hal ini dilakukan untuk mendapatkan dan menggali informasi tentang apa permasalahan serta apa yang dibutuhkan objek pada saat ini, setelah ditemukan permasalahan maka tahap berikutnya adalah membuat proposal untuk melakukan pengabdian dan apabila di acc maka dilanjutkan dengan pembuatan modul dan bahan pelatihan, setelah itu maka pelaksanaan pelatihan bias dilakukan, di saat pelaksanaan dilakukan disitu pula tim pengabdian membuatkan website promosi untuk bimbel dharma putra, setelah pelaksanaan pelatihan dilakukan dan website sudah jadi maka dilakukan hibah atau penyerahan website ke pihak bimbel dharma putra, setelah semuanya selesai dilakukan monitoring serta evaluasi kegiatan untuk mendapatkan data apakah pengabdian dilaksankaan dengan baik, dan tahap terakhir adalah pembuatan laporan pengabdian kepada masyarakat.

Sebenarnya kegiatan pelatihan micro teaching ini direncanakan dilakukan secara langsung, namun karena pandemi covid - 19 yang belum pasti kapan akan berakhir maka diputuskan lah wawancara dan pelatihan dilakukan secara daring, yaitu dengan menggunakan aplikasi zoom, hal ini dilakukan agar antara tutor dan pengajar di bimbel dharma putra, dapat bertemu secara 
virtual, dan materi dapat tersampaikan dengan baik.

Adapun manfaat yang diperoleh dari pengabdian masyarakat yang dilakukan ini adalah sebagai berikut :

1. Bimbel dharma putra mendapatkan sebuah website yang dapat dipergunakan untuk mempromosikan serta menyebarkan informasi secara lebih cepat dan tepat

2. Bimbel dharma putra dapat meningkatkan daya saingnya karna sudah memiliki website

3. Terciptanya pengajar yang unggul dan handal dalam mengajar karena sudah mendapatkan pelatihan micro teaching

4. Para pengajar di bimbel dharma putra dapat memanajemen waktu mengajarnya menjadi lebih baik, dan skill mengajarnya menjadi lebih meningkat.

\section{HASIL DAN PEMBAHASAN}

Hasil dan pembahasan disusun secara sistematis berdasarkan metode yang telah di bahas pada bagian sebelumnya, adapun masing masing penjelasan dijabarkan sebagai berikut:

\section{Pencarian Objek Pengabdian}

Tahap pertama dari pengabdian masyarakat ini adalah mencari objek tempat tim kami akan melakukan pengabdian. Setelah melakukan diskusi dengan tim ditentukanlah bahwa pengabdian akan dilakukan di bimbel dharma putra.

Bimbel dharma putra memiliki dua buah cabang di sekitar kota Pontianak, yaitu di kelurangan siantan hilir dan dikelurahan Saigon Pontianak, dengan memiliki murid yang cukup banyak sekitar 35 - 50 orang dengan tenaga pengajar kurang lebih 9 orang di setiap cabangnya, adapun masing masing cabang bimbel dharma putra dapat dilihat pada Gambar 2.

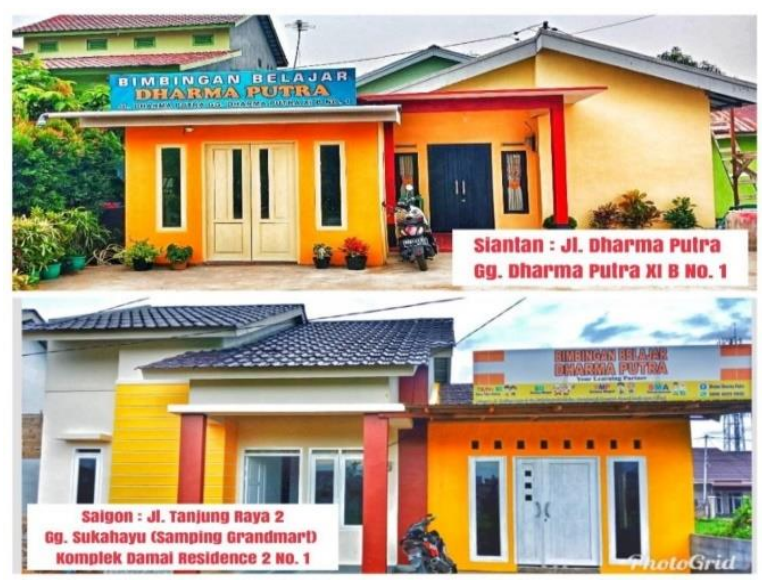

Gambar 2 : Foto Lokasi Bimbel Dharma Putra

\section{Observasi dan Wawancara}

Setelah menentukan objek pengabdian, maka berikutnya tim kami mulai melakukan observasi dan wawancara langsung ke objek, dimana ketika observasi kami mendatangi lokasi bimbel dharma putra, hal ini dilakukan untuk mengetahui permasalahan yang terjadi selama ini, dan ketika melakukan observasi langsung ke lokasi ada beberapa permasalahan yang ditemui yaitu :

a. Lokasi bimbel dharma putra tidak berada di jalan raya, namun masuk kedalam gang dan perumahan.

b. Bimbel dharma putra kurang dikenal oleh lingkungan sekitar, terbukti ketika kami bertanya kepada beberapa orang yang agak jauh mereka tidak mengetahui lokasi bimbel dharma putra

c. Tidak ada media promosi seperti poster dan spanduk yang disebar oleh pemilik untuk memperkenalkan bimbel dharma putra di sekitar lokasi.

d. Selama ini promosi hanya dilakukan melalui social media dan dari mulut kemulut.

Setelah observasi dilakukan untuk lebih meyakinkan kami akan permaslahan yang didapat setelah observasi maka tim melakukan wawancara langsung kepada pemilik bimbel dharma putra, yaitu bapak yuda firlana S.Pdi, dari wawancara beberapa permasalahan ditemukan yaitu :

a. Bimbel dharma putra kesulitan untuk membuat media promosi seperti poster dan selebaran, karena akan mengeluarkan biaya yang cukup tinggi

b. Lokasi bimbel yang didalam gang menyebabkan masyarakat kurang mengetahui lokasi bimbel tersebut.

c. Bimbel dharma putra membutuhkan sebuah media promosi milik sendiri tidak hanya social media saja

d. Guru guru di bimbel dharma putra membutuhkan pelatihan terkait cara mengajar dan memanajemen waktu mengajar

Dari observasi dan wawancara yang telah dilakukan maka dari itu tim pengabdian masyarakat menyimpulkan bahwa untuk membantu Bimbel Dharma Putra keluar dari pemasalahannya yaitu harus membuat sebuah website sebagai media promosi dan mengadakan sebuah pelatihan micro teaching untuk para guru guru pengajar di bimbel tersebut.

\section{Pelaksanaan Pelatihan dan Penyerahan Hibah Website Promosi}

Setelah mengetahui permasalahan dan mengurus administrasi untuk melakukan pelatihan 
maka berikutnya tim mempersiapkan diri seperti membuat modul untuk pelatihan, dan membuat sebuah website promosi untuk bimbel dharma putra.

Dikarenakan masa pandemi Covid 19 maka dari itu diputuskan pelatihan dilakukan secara daring, menggunakan aplikasi zoom, pelaksanaan pelatihan dilakukan 3 kali dalam sebulan, adapun beberapa dokumentasi dari pelatihan yang dilakukan secara daring dapat dilihat pada pada gambar 3 .
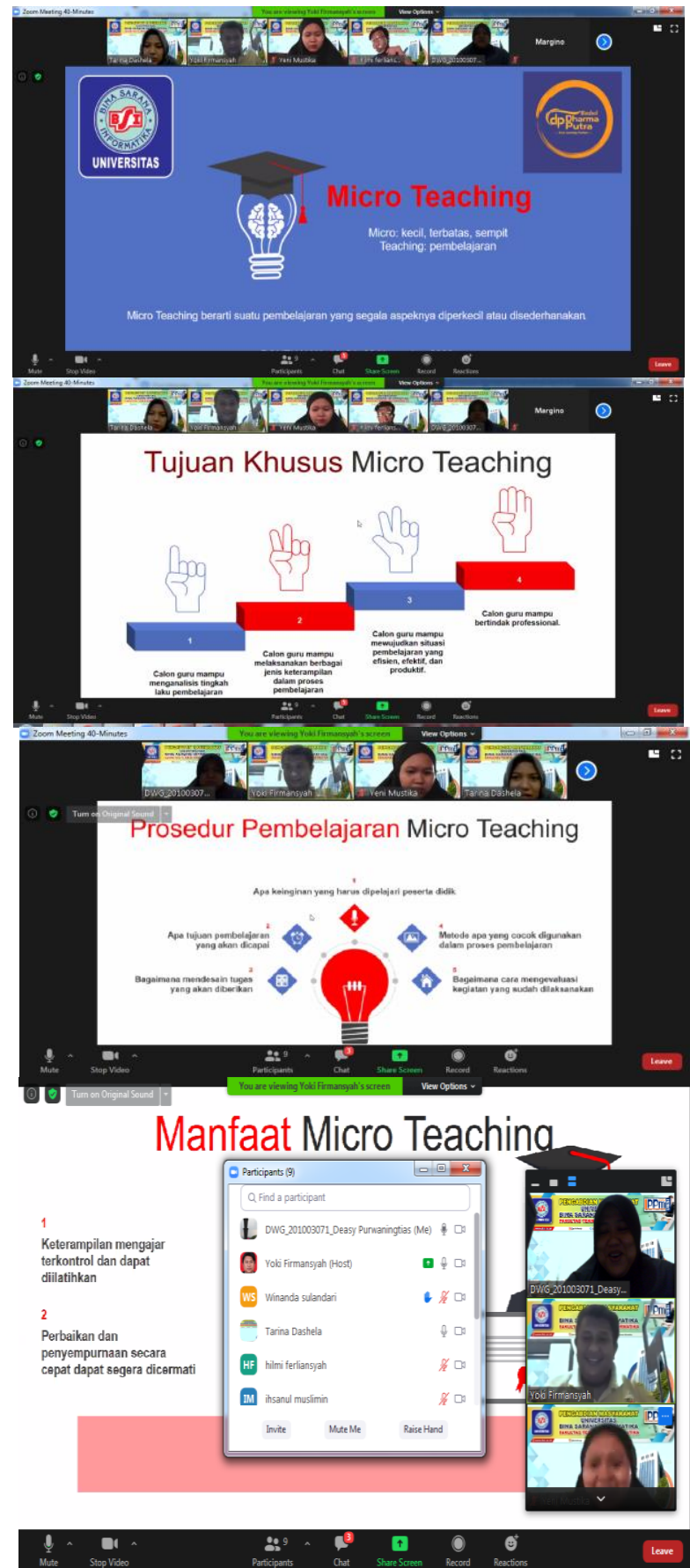

Gambar 3. Pelatihan Micro Teaching Secara Daring
Terlihat pada gambar 3 diatas bahwa pelatihan micro teaching dilakukan secara daring menggunakan aplikasi zoom meeting, hal ini dilakukan karena memang adanya aturan tidak boleh berkumpul, pelatihan dilakukan sebanyak 4 kali dalam sebulan.

\section{Monitoring Dan Evaluasi}

Setelah pelatihan dan hibah dilakukan tentunya perlu dilakukan monitoring dan evaluasi, adapun hasil evaluasi dari kegiatan pengabdian masyarakat ini yaitu sebagai berikut :

1. Untuk memonitoring kegiatan ini maka tim pengabdian masyarakat melakukan pengecekan langsung apakah kegiatan pelatihan berjalan dengan lancar.

2. Mencatat permasalahan permasalahan yang terjadi agar dapat diperbaiki di kegiatan pengabdian berikutnya

3. Mendokumentasikan absensi secara manual untuk memastikan panitia dan peserta mengikuti dengan baik setiap pelatihan yang dilakukan.

Untuk mengukur keberhasilan dari pengabdian masyarakat ini dan sebagai bahan sevaluasi, tim pengabdian masyarakat menyebarkan kuesioner Adapun beberapa pertanyaan yang diajukan kepeserta terlihat pada tabel 1.

Tabel 1. Pertanyaan Kuesioner Evaluasi Pengabdian Masyarakat

\begin{tabular}{|c|c|}
\hline Kode & Pertanyaan \\
\hline P1 & $\begin{array}{l}\text { Personil/anggota yang terlibat dalam kegiatan } \\
\text { pengabdian masyarakat memberikan pelayanan } \\
\text { sesuai dengan kebutuhan peserta }\end{array}$ \\
\hline $\mathrm{P} 2$ & $\begin{array}{l}\text { Tutor menyampaikan materi kegiatan dengan jelas } \\
\text { dan mudah dimengerti oleh peserta }\end{array}$ \\
\hline P3 & $\begin{array}{l}\text { Setiap keluhan/pertanyaan/permasalahan yang } \\
\text { diajukan ditindaklanjuti dengan baik oleh tutor yang } \\
\text { terlibat }\end{array}$ \\
\hline $\mathrm{P} 4$ & $\begin{array}{l}\text { Materi yang disampaikan sesuai dengan kebutuhan } \\
\text { peserta dalam menambah wawasan, pengetahuan, } \\
\text { keterampilan dan keahlian peserta }\end{array}$ \\
\hline P5 & $\begin{array}{l}\text { Peserta mendapatkan materi kegiatan berupa modul } \\
\text { dan soal latihan }\end{array}$ \\
\hline P6 & Peralatan untuk menyampaikan materi memadai \\
\hline P7 & $\begin{array}{l}\text { Kegiatan pengabdian masyarakat yang disampaikan } \\
\text { bermanfaat untuk menambah wawasan, } \\
\text { pengetahuan, keterampilan dan keahlian peserta }\end{array}$ \\
\hline P8 & $\begin{array}{l}\text { Saya merasa puas dengan kegiatan pengabdian } \\
\text { masyarakat yang diselenggarakan Universitas Bina } \\
\text { Sarana Informatika }\end{array}$ \\
\hline P9 & $\begin{array}{l}\text { Kegiatan pengabdian masyarakat yang } \\
\text { diselenggarakan Universitas Bina Sarana Informatika } \\
\text { sesuai dengan harapan saya }\end{array}$ \\
\hline P10 & $\begin{array}{l}\text { Jika kegiatan ini diselenggarakan kembali, saya } \\
\text { bersedia untuk berpartisipasi/terlibat }\end{array}$ \\
\hline
\end{tabular}


Kuesioner yang berisi pertanyaan yang terlihat pada table 1 tersebut diberikan Ketika pengabdian berakhir, dan hasil dari kuesioner yang dibagikan yaitu :

1. Pertanyaan p1, dari 8 responden yang merupakan peserta pengabdian 7 diantaranya mengatakan puas, dan hanya 1 yang tidak puas

2. Pertanyaan p2, 8 responden yang mengisi menyatakan puas

3. Pertanyaan p3, dari 8 responden 7 menyatakan puas dan 1 menyatakan tidak puas

4. Pertanyaan $\mathrm{P} 4,8$ responden mengatakan puas

5. Pertanyaan $\mathrm{p} 5,8$ responden menyatakan puas

6. Pertanyaan p6, 5 responden menyatakan puas dan 3 responden menyatakan tidak puas

7. Pertanyaan p7. Semua Responden menyatakan puas

8. Pertanyaan p8, semua responden menyatakan puas

9. Pertanyaan $\mathrm{p} 9$, semua responden menyatakan puas

10.Pertanyaan $\mathrm{p} 10$, semua responden menyatakan puas

Selain itu terdapat pendapat dan saran yang diberikan dari responden yang dijabarkan pada tabel 2.

Tabel 2. Pendapat Dan Saran Responden Pengabdian Masyarakat

\begin{tabular}{cll}
\hline Kode & \multicolumn{1}{c}{ Pendapat } & \multicolumn{1}{c}{ Saran } \\
\hline R1 & $\begin{array}{l}\text { Sangat bagus dan } \\
\text { menambah wawasan }\end{array}$ & $\begin{array}{l}\text { Dilakukan Secara } \\
\text { Offline }\end{array}$ \\
\hline R2 & $\begin{array}{l}\text { sangat baik dan } \\
\text { bermanfaat bagi } \\
\text { masyarakat }\end{array}$ & - \\
\hline R3 & sangat berguna dan baik & - \\
\hline R4 & - & \\
\hline R5 & - & - \\
\hline R6 & sangat baik sekali & $\begin{array}{c}\text { lebih ke kekegiatan } \\
\text { anak muda }\end{array}$ \\
\hline R7 & Sangat Bermanfaat & $\begin{array}{c}\text { Kegiatan Yang lebih } \\
\text { bersifat sosial }\end{array}$ \\
\hline R8 & $\begin{array}{c}\text { Sangat bagus dan } \\
\text { menambah wawasan } \\
\text { saya }\end{array}$ & $\begin{array}{c}\text { sebaiknya dilakukan } \\
\text { secara offline }\end{array}$ \\
\hline
\end{tabular}

Dan sebagai hasil atau luaran dari pengabdian ini tim membuat press release kegiatan yang dimuat pada media massa yang terlihat pada gambar 6 .

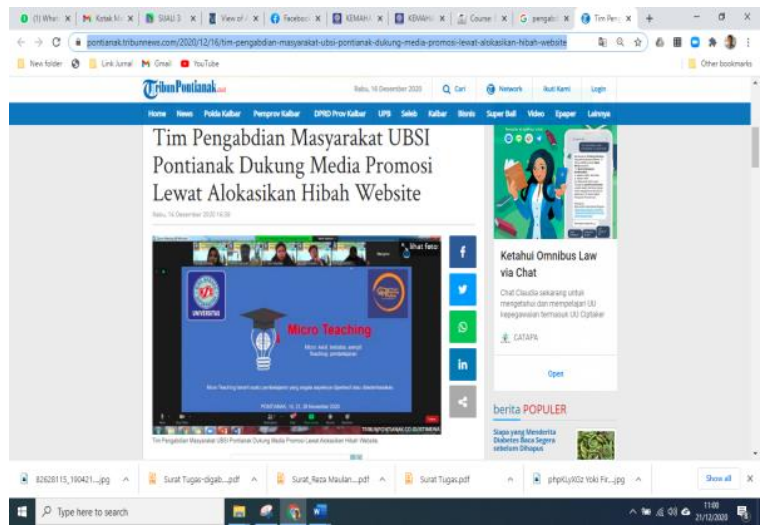

Gambar 6. Press release Kegiatan

KESIMPULAN

Kegiatan pengabdian masyarakat yang dilaksanakan di bimbel dharma putra ini terselenggara dengan sangat baik dan berjalan dengan cukup lancar, hal ini terlihat dari hasil evaluasi yang menyatakan puas dengan pengabdian masyarakat ini. dan ketika menyerahkan hibah website tetap menjaga protokol kesehatan, pelatihan sendiri disambut dengan baik dan antusias oleh para guru di bimbel dharma putra dan mengucapkan rasa terima kasih kepada tim pengabdian karena sangar bermanfaat untuk mereka.

Beberapa kendala ditemui ketika pelaksanaan mulai dari karena adanya pandemic covid hingga minimnya pengetahuan pemilik tentang website mengakibatkan perlunya pembelajaran secara lanjut selain itu melihat kuesioner evaluasi terlihat ada ketidak puasan dari peserta karena pelatihan micro teaching dilakukan secara daring.

\section{SARAN}

Ada berberapa saran yang didapatkan dari pengabdian masyarakat yang dilakukan di bimbel dharma putra ini yaitu sebaiknya ketika masa pandemic berakhir kegiatan ini dilakukan secara langsung mengingat sulitnya berinteraksi dengan zoom, karena pergerakan sangat terbatas, selain itu pihak bimbel dharma putra harus menyediakan satu tenaga khusus sebagai pengelola website agar dapat selalu update dan bejalan dengan baik.

\section{DAFTAR REFERENSI}

[1] Y. Firmansyah and Pitriani, "Penerapan Metode SDLC Waterfall Dalam Pembuatan Aplikasi Pelayanan Anggota Pada CU Duta Usaha Bersama Pontianak," J. Bianglala 
Inform., vol. 5, no. 2, pp. 66-74, 2017.

[2] P. S. Hasugian, "Perancangan Website Sebagai Media Promosi Dan Informasi," J. Inform. Pelita Nusant., vol. 3, no. 1, pp. 8286, 2018.

[3] Y. Firmansyah, "Penerapan Metode SDLC Waterfall Dalam Pembuatan Sistem Informasi Akademik Berbasis Web Studi Kasus Pondok Pesantren Al-Habi Sholeh Kabupaten Kubu Raya , Kalimantan Barat," J. Teknol. Manaj. Inform., vol. 4, no. 1, pp. 185-191, 2018.

[4] V. M. M. Siregar, "Perancangan Website Sebagai Media Promosi Dan Penjualan Produk," TAM (Technology Accept. Model., vol. 9, no. 1, pp. 15-21, 2018.

[5] Firmansyah, "Sistem Informasi Pengaduan Warga Berbasis Website ( Studi Kasus: Kelurahan Siantan Tengah , Pontianak Utara )," J. Cendikia, vol. XIX, no. April, pp. 397-404, 2020, [Online]. Available: https://jurnal.dcc.ac.id/index.php/JC/articl e/view/328.

[6] A. Sasongko, "Dan Teknologi Komputer Integrasi Data Website Students . Bsi . Ac . Id Untuk Mobile Infokampus Berbasis Android Menggunakan," Sasongko Agung, vol. 2, no. 2, pp. 146-155, 2017, [Online]. Available:

https://scholar.google.co.id/citations?user =OuivAEkAAAAJ\&hl=id\&oi=ao\#d=gs_md_ci ta-

$\mathrm{d} \& \mathrm{p}=\& \mathrm{u}=\% 2 \mathrm{Fcitations} \% 3 \mathrm{Fview}$ _op $\% 3 D v i e$ w_citation\%26hl\%3Did\%26user\%3DOuivA EkAAAAJ\%26citation_for_view\%3DOuivAE kAAAAJ\%3ATyk-4Ss8FVUC\%26tzom\%3D420.

[7] M. Ardi, "Pelaksanaan pembelajaran bagi mahasiswa program studi PPKn STKIPPGRI Pontianak," J. Edukasi, vol. 1, no. 88, pp. 75-84, 2014.

[8] E. P. Ningrum, T. Yoganingsih, N. Ratriningtyas, W. Winarso, and N. W. Setyawati, "Pelatihan Pembukuan Sederhana, Sosialisasi Perpajakan dan Pengelolaan Manajemen Bagi UMKM IbuIbu Catering Perumahan Jatimulya RW. 012," J. ABDIMAS (Pengabdian Kpd. Masyarakat) UBJ, vol. 2, no. 2, pp. 126-130, 2019. 